\title{
Cellular Response of Ventricular-Subventricular Neural Progenitor/Stem Cells to Neonatal Hypoxic-Ischemic Brain Injury and Their Enhanced Neurogenesis
}

\author{
Jeong Eun Shin ${ }^{1}$, Haejin Lee ${ }^{2}$, Kwangsoo Jung ${ }^{1}$, Miri Kim², Kyujin Hwang 3 , \\ Jungho Han ${ }^{1}$, Joohee Lim ${ }^{1}$, Il-Sun Kim ${ }^{1}$, Kwang-Il Lim ${ }^{4}$, and Kook In Park ${ }^{1,2,3}$ \\ ${ }^{1}$ Division of Neonatology, Severance Children's Hospital, Department of Pediatrics, Yonsei University College of Medicine, Seoul; \\ ${ }^{2}$ Yonsei Biomedical Research Institute, Yonsei University College of Medicine, Seoul; \\ ${ }^{3}$ Brain Korea 21 Plus Project for Medical Science, Yonsei University College of Medicine, Seoul; \\ ${ }^{4}$ Department of Chemical and Biological Engineering, Sookmyung Women's University, Seoul, Korea.
}

\begin{abstract}
Purpose: To elucidate the brain's intrinsic response to injury, we tracked the response of neural stem/progenitor cells (NSPCs) located in ventricular-subventricular zone (V-SVZ) to hypoxic-ischemic brain injury (HI). We also evaluated whether transduction of V-SVZ NSPCs with neurogenic factor NeuroDl could enhance their neurogenesis in HI.

Materials and Methods: Unilateral HI was induced in ICR neonatal mice. To label proliferative V-SVZ NSPCs in response to HI, bromodeoxyuridine (BrdU) and retroviral particles encoding LacZ or NeuroD1/GFP were injected. The cellular responses of NSPCs were analyzed by immunohistochemistry.

Results: Unilateral HI increased the number of BrdU+ newly-born cells in the V-SVZ ipsilateral to the lesion while injury reduced the number of newly-born cells reaching the ipsilateral olfactory bulb, which is the programmed destination of migratory V-SVZ NSPCs in the intact brain. These newly-born cells were directed from this pathway towards the lesions. HI significantly increased the number of newly-born cells in the cortex and striatum by the altered migration of V-SVZ cells. Many of these newly-born cells differentiated into active neurons and glia. LacZ-expressing V-SVZ NSPCs also showed extensive migration towards the non-neurogenic regions ipsilateral to the lesion, and expressed the neuronal marker NeuN. NeuroD1 ${ }^{+} / \mathrm{GFP}^{+} \mathrm{V}-\mathrm{SVZ}$ NSPCs almost differentiated into neurons in the peri-infarct regions.

Conclusion: HI promotes the establishment of a substantial number of new neurons in non-neurogenic regions, suggesting intrinsic repair mechanisms of the brain, by controlling the behavior of endogenous NSPCs. The activation of NeuroD1 expression may improve the therapeutic potential of endogenous NSPCs by increasing their neuronal differentiation in HI.
\end{abstract}

Key Words: Neural stem cells, hypoxia-ischemia, brain, cell proliferation, cell movement, cell differentiation

Received: February 20, 2020 Revised: April 10, 2020

Accepted: April 18, 2020

Corresponding author: Kook In Park, MD, PhD, Division of Neonatology, Severance Children's Hospital, Department of Pediatrics, Yonsei University College of Medicine, 50-1 Yonsei-ro, Seodaemun-gu, Seoul 03722, Korea.

Tel: 82-2-2228-2059, Fax: 82-2-393-9118, E-mail: kipark@yuhs.ac

-The authors have no potential conflicts of interest to disclose.

(C) Copyright: Yonsei University College of Medicine 2020

This is an Open Access article distributed under the terms of the Creative Commons Attribution Non-Commercial License (https://creativecommons.org/licenses/ by-nc/4.0) which permits unrestricted non-commercial use, distribution, and reproduction in any medium, provided the original work is properly cited.

\section{INTRODUCTION}

Neonatal hypoxic-ischemic brain injury (HI) remains one of the most common causes of death and severe neurologic morbidity in infants and children, resulting in chronic cognitive, motor, and sensory deficits. ${ }^{1,2}$ However, currently, there is no therapy to repair the HI except therapeutic hypothermia, which offers very limited functional recovery. ${ }^{3,4}$ Consequently, the development of supplementary or alternative therapies, that act synergistically with hypothermia or are effective when used alone, are needed to reduce the mortality and morbidity in 
newborn infants with HI.

It is conventionally accepted that neuronal generation does not take place beyond fetal life, and therefore, neuronal regeneration does not occur in the vast majority of the post-developmental "non-neurogenic" central nervous system (CNS) after injury or disease. ${ }^{5}$ However, neurogenesis from neural stem/progenitor cells (NSPCs) in two restricted neurogenic niches-ventricular-subventricular zone (V-SVZ) near the lateral ventricles and hippocampal subgranular zone - of the mammalian CNS has great implications for the growing field of research on endogenous NSPCs in the mature nervous system. ${ }^{6-16}$ Manipulation of these actively dividing or relatively quiescent NSPCs could supply cell population with immense neuroregenerative potential. Stimulated endogenous NSPCs could be a source of new neurons or glial cells that replace lost neural cells in CNS diseases. Notably, the V-SVZ peaks in size during the first week of postnatal development in rodents and at approximately the 35th week of gestation in humans as a result of extensive cell proliferation. ${ }^{17}$ The human neonatal V-SVZ has a remarkable neurogenic capacity, ${ }^{18,19}$ suggesting that NSPCs in V-SVZ may provide an endogenous cell population for neural regeneration after neonatal brain injury.

As a model for HI, we employed the Rice-Vannucci mode ${ }^{20}$ which has been most well-accepted as rendering one of the experimentally destructive injuries: permanently ligating unilateral common carotid artery on postnatal day 7 (P7) followed by hypoxia $\left(8-10 \% \mathrm{O}_{2}\right)$. This procedure results in extensive $\mathrm{HI}$ that severely damages the ipsilateral cerebral hemisphere, including non-neurogenic regions such as the sensorimotor cortex, subcortex, and striatum, while preserving the contralateral hemisphere as an intact control. We believed that such a model would support an ideal opportunity to estimate the response of endogenous NSPCs to a devastating, clinically-relevant severe $\mathrm{HI}$.

In this study, we tracked the response of endogenous V-SVZ NSPCs to a severe clinically relevant neonatal HI to investigate the brain's intrinsic repair mechanism to injury, by using retroviral vectors transducing the $L a c Z$ reporter gene and by bromodeoxyuridine (BrdU) to label proliferative NSPCs. In addition, we also evaluated whether a retroviral transduction of V-SVZ NSPCs with neurogenic gene NeuroD1 could enhance their neurogenesis in $\mathrm{HI}$, which may enhance therapeutic potential of endogenous NSPCs in CNS disorders.

\section{MATERIALS AND METHODS}

\section{Induction of unilateral HI brain injury}

Through a ventral midline neck incision, the right common carotid artery of anesthetized ICR (CD1) mice on postnatal day 7 (P7) was permanently ligated with the surgical suture silk. After the incision was closed, the animals were kept warm until awake and returned to their dams for $3 \mathrm{~h}$. The pups were then placed in an acrylic chamber with hypoxic atmosphere of $92 \% \mathrm{~N}_{2}$ and $8 \% \mathrm{O}_{2}$ for $2.2 \mathrm{~h}$. The animals' body temperature was maintained at $37^{\circ} \mathrm{C}$.

\section{BrdU labeling and detection}

Two hours after the induction of unilateral HI, the mice were intraperitoneally administered $50 \mathrm{mg} / \mathrm{kg}$ bromodeoxyuridine (BrdU; Sigma, St. Louis, MO, USA) every $4 \mathrm{~h}$ for the subsequent $12 \mathrm{~h}$ (four administrations total). The animals were sacrificed $24 \mathrm{~h}(\mathrm{n}=3), 48 \mathrm{~h}(\mathrm{n}=3), 1 \mathrm{wk}(\mathrm{n}=7), 2 \mathrm{wk}(\mathrm{n}=5)$, and $3 \mathrm{wk}$ $(n=5)$ after the final BrdU "pulse" and processed for BrdU detection. In some experiments designed to assess the long-term in vivo survival and permanence of BrdU-intercalated cells over months, daily "pulses" of BrdU for a week post-HI were performed. At the pre-determined timepoints for analysis, the animals were deeply anesthetized and perfused transcardially with 0.1 M PIPES buffer (pH 6.9; Sigma) containing 4\% paraformaldehyde. The brain was subsequently post-fixed in the perfusing solution overnight at $4^{\circ} \mathrm{C}$, cryoprotected overnight in phosphate-buffered saline (PBS) containing $30 \%$ sucrose at $4^{\circ} \mathrm{C}$, and then embedded in O.C.T compound medium (Sakura Finetek, Torrance, CA, USA). Serial brain coronal cryostat sections $(15-\mu \mathrm{m}$ thick) were treated initially with $2 \mathrm{~N} \mathrm{HCl}$ for 30 $\min$ at $37^{\circ} \mathrm{C}$ to denature cellular DNA and then reacted with a Fluorescein isothiocyanate (FITC)-conjugated mouse antiBrdU antibody and/or a mouse anti-BrdU antibody (Boehringer Mannheim, Indianapolis, IN, USA) followed by a biotinylated-horse anti-mouse secondary antibody (Vector Laboratories, Burlingame, CA, USA), in order to identify BrdU-labeled cells.

\section{Injection of retrovirus and detection}

Retrovirus vector particles encoding lac $Z$ were collected from the supernatants of confluent $\psi 2$ BAG helper virus-free packaging cells for $48 \mathrm{~h}$ at $37^{\circ} \mathrm{C}$, filtered through $0.45 \mu \mathrm{m}$ pores, aliquoted, and stored at $-80^{\circ} \mathrm{C}^{21}$ The BAG virus stock $\left(8 \times 10^{7} \mathrm{G} 418\right.$ resistant $\mathrm{CFU} / \mathrm{mL}$ ) was mixed with $8 \mu \mathrm{g} / \mathrm{mL}$ polybrene and trypan blue prior to gently expelling $2 \mu \mathrm{L}$ through a finely drawn glass micropipette into each lateral ventricle of mice $2 \mathrm{~h}$ before the induction of HI. The brains were processed via standard methods described below and elsewhere for immunohistochemisty. ${ }^{22}$ Expression of the lacZ gene product, $E$. coli $\beta$-galactosidase ( $\beta g a l)$, was detected by rabbit anti- $\beta$ gal antibody (1:1000; Cappel Laboratories, Cochranville, PA, USA) followed by Texas red (TR)-conjugated goat anti-rabbit IgG (1:200; Vector Laboratories) antibodies.

The pCLPIT GFP plasmid was used to produce the murine leukemia virus (MLV)-based retroviral vector expressing $\mathrm{GFP}^{23}$ The pCAG-NeuroD1-IRES-GFP sequence was subcloned from CAG-NeuroD1-IRES-GFP plasmid (Addgene, Watertown, MA, USA) and replaced the PuroR-IRES-tTA/TRE-GFP sequence in the pCLPIT GFP plasmid to generate the mouse NeuroD1/GFPexpressing retroviral vector. Retrovirus vector particles encod- 
ing GFP or NeuroD1/GFP were collected from the supernatants of human embryonic kidney $293 \mathrm{~T}$ cells and concentrated to about $10^{8} \mathrm{TU} / \mathrm{mL}$ by ultracentrifugation. ${ }^{24}$ The virus stock solution was injected into each lateral ventricle of mice being subjected to $\mathrm{HI}$, and the brains were processed as described above. The expressions of GFP and NeuroD1 gene products were detected by rabbit or mouse anti-GFP (1:100; Thermo Fisher Scientific, Waltham, MA, USA) and mouse anti-NeuroD1 (1:500; Abcam, Cambridge, MA, USA) antibodies, respectively. Species-specific secondary antibodies, conjugated with FITC (1:200; Vector Laboratories) or TR (1:200; Vector Laboratories), were used to detect the binding of primary antibodies.

\section{Immunohistochemistry}

Immunohistochemistry (IHC) analysis ${ }^{25}$ employed the antiBrdU, anti-ßgal, anti-GFP, and/or anti-NeuroD1 antibodies described above. Dual staining was performed with primary antibodies against the following immature, undifferentiated NSPC and established differentiated neural cell type-specific antigens: anti-NeuN (1:100; Chemicon, Billerica, MA, USA), antineurofilament (NF) (1:500; Sternberger, San Diego, CA, USA), anti-Doublecortin (DCX) (1:50, Santa Cruz, CA, USA), antiOlig2 (1:200; Millipore, Billerica, MA, USA), anti-CNP'ase (1:500, Sternberger), anti-glial fibrillary acidic protein (GFAP) (1:1000; Dako, Glostrup, Denmark), anti-nestin (1:500; PharMingen, San Diego, CA, USA). Nuclear c-fos and synaptic connection with neighboring neurons were detected by a rabbit polyclonal antic-fos (1:10000; Santa Cruz) and anti-synapsin 1 (1:500; Thermo Fisher Scientific) antibodies, respectively. Species-specific secondary biotinylated (Vector Laboratories), streptavidin TRconjugated (1:200; Jackson, Cambridge, UK), FITC-conjugated, or TR-conjugated antibodies were used to detect the binding of primary antibodies. Specimens were mounted using the Vectashield mounting medium with 4,6-diamino-2-phenylindole (DAPI; Vector Laboratories), and were analyzed by an immunofluorescence microscopy (BX51; Olympus, Center Valley, PA, USA) or a confocal laser scanning microscopy (LSM 700; Carl Zeiss, Oberkochen, Germany).

\section{Quantification}

Structures were sampled by selecting predetermined areas on each coronal section as described. ${ }^{26}$ Every 6 th section was selected from a coronal series through the striatum between the following points relative to bregma: $+0.98 \mathrm{~mm}$ (genu of the corpus callosum) and $+0.14 \mathrm{~mm}$ (anterior commissure crossing). Proliferating cells were ascertained by their BrdU incorporation, and their quantification was based on counts of BrdU-immunoreactive cells using the optical dissector stereological method. ${ }^{27}$ $\mathrm{BrdU}^{+}$cells were counted in three predetermined ventral, lateral, and dorsal squares $(50 \times 50 \mu \mathrm{m})$ of the lateral ventricle wall on all selected sections. A rectangular area of the striatum (300x $600 \mu \mathrm{m})$ was selected at a $50-\mu \mathrm{m}$ distance from the lateral ventricle wall and analyzed on each section. All BrdU' nuclei in these areas were counted. Every 12th section from a coronal series [spanning from the olfactory bulb (OB) and frontal cortex rostrally and progressing caudally through the entire telencephalon] was selected and processed for BrdU IHC. As depicted, ${ }^{26}$ four predetermined areas $(50 \times 50 \mu \mathrm{m})$ in the rostral migratory stream (RMS) and granule cell layer of the OB were analyzed on each section. All BrdU ${ }^{+}$nuclei in these areas were counted.

\section{Statistical analysis}

All statistical analyses were performed using SPSS version 23 (IBM Corp., Armonk, NY, USA). For statistical comparison of newly-born BrdU ${ }^{+}$cell numbers, we performed two-way ANOVA to account for the effect of HI (non-injured vs. injured mice) and/or hemispheres (contralateral vs. ipsilateral hemisphere). Bonferroni post hoc analysis was sequentially performed for pairwise comparisons of groups at each timepoints where appropriate. Sample sizes were calculated using power analyses with an $\alpha$-level of 0.05 and a power of 0.8 . Data are presented as the means \pm SEM. $p<0.05$ was considered statistically significant.

\section{RESULTS}

\section{Proliferation and migration patterns of BrdU-labeled endogenous NSPCs in response to unilateral HI}

Following unilateral $\mathrm{HI}$, the proliferation and migration patterns of endogenous NSPCs in the periventricular regions of both hemispheres was assessed using the serial BrdU injection method. BrdU was selectively and permanently incorporated into the nuclear genomic material of all proliferating cells entering S-phase. ${ }^{10-14} \mathrm{HI}$ induced a significantly increased proliferation of BrdU-labeled V-SVZ NSPC population ipsilateral to the lesioned right side (Figs. 1 and 2). Furthermore, HI appeared to induce a significant redistribution of proliferative NSPCs ipsilateral to the lesioned right side (Fig. 1B, D, F, and H) compared to the grossly intact contralateral left side (Fig. 1A, $\mathrm{C}, \mathrm{E}$, and $\mathrm{G}$ ) and uninjured control group ( $\mathrm{n}=5$ ) (Fig. 2). The accumulation of $\mathrm{BrdU}^{+}$cells was actually most pronounced in the dorsolateral wall of the lateral ventricles, particularly the anterior one-third of the V-SVZ (Fig. 1B, D, F, and H), adjacent to the infarction cavity (IC) (Fig. 1B, D, and F); and a relatively dense "stream" of newly-born cells (arrowhead in Fig. 1B) oriented towards and into the extensively injured cortex was now apparent (arrows in Fig. 1B, D, F, H, and F'). The actual number of newly-born cells was, indeed, increased at the site of $\mathrm{HI}$ and its penumbra in the neocortex as well as in adjacent parenchymal areas, particularly in the striatum (Fig. 1D, F, F, and Fig. 2). About 2-4 times as many BrdU ${ }^{+}$cells were seen in the ipsilateral cortex and striatum 24-48 h after BrdU pulse compared to uninjured controls [e.g., cortex: 1964.2 \pm 246.5 (mean \pm SEM) vs. $495.6 \pm 78.8, p<0.05$; striatum: $2950.8 \pm 331.8$ vs. $657.6 \pm$ 

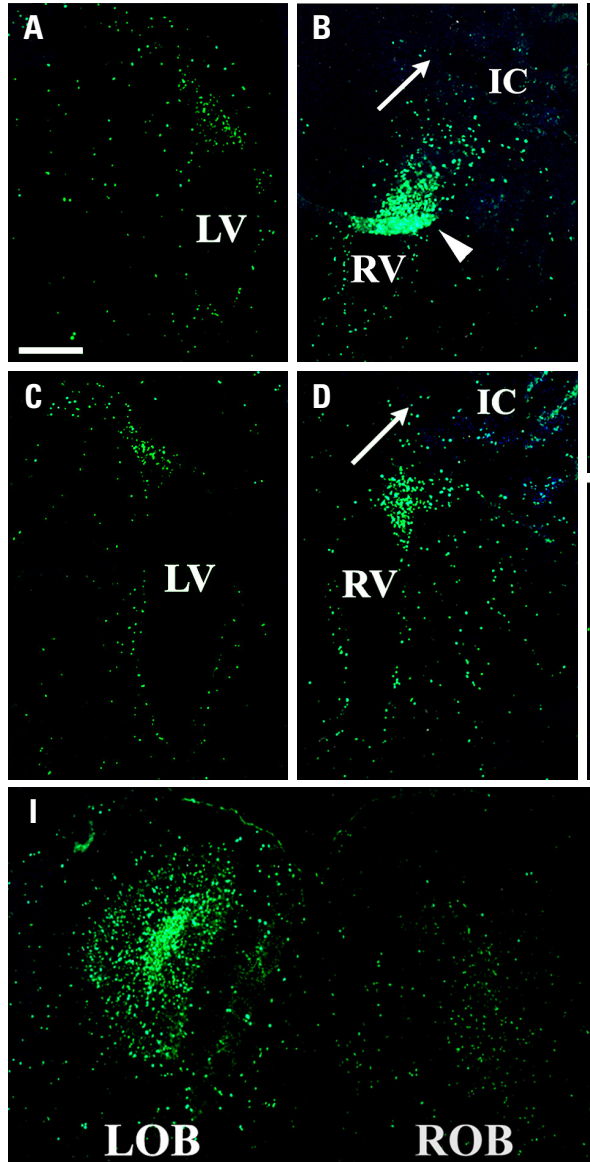

Fig. 1. Proliferation and migration patterns of BrdU-labeled endogenous NSPCs in response to unilateral HI. The schematic (K) shows the level of coronal section represented by each of following immunostained panels: the section through "a" is seen in (I); section through "b" is seen in (J); sections through " $c$ " are seen in (A and B); sections through " $d$ " are seen in $(C$ and $D)$; sections through " $e$ " are seen in $\left(E, F\right.$, and $\left.F^{\prime}\right)$. The marked $\left({ }^{*}\right)$ areas in $(E$ and $F)$ are magnified in $(G$ and $H)$, respectively. The shaded region in $(K)$ delineates the approximate area of injury in the right hemisphere [the side ipsilateral to (B, $D$, $\mathrm{F}, \mathrm{H}, \mathrm{F}^{\prime}$ and "ROB" in I and J)]. The normal fate of V-SVZ NSPCs is to migrate rostrally to the OB via the RMS. Accordingly, few of BrdU" (green) V-SVZ NSPCs (particularly the anterior portion) on the intact left side (e.g., A and C) remain there; rather most have appropriately left the V-SVZ and migrated out rostrally to and become integrated in the LOB in (I and J). Strikingly, on the side ipsilateral to the injury on the right, BrdU ${ }^{+}$cells in the V-SVZ [e.g., arrowhead in (B)] appear to have been directed from migrating out rostrally to the ROB in (I and $\mathrm{J}$ ) (where the number of BrdU ${ }^{+}$cells is significantly diminished compare with adjacent $L O B$ ), but rather have remained near the injured brain in and around the V-SVZ and adjacent cortex and striatum. Arrows in (B, D, $\mathrm{F}, \mathrm{H}$, and $\mathrm{F}^{\prime}$ ) points to the extensive adjacent areas of degeneration emanating from the IC. HI induced increased accumulation of BrdU ${ }^{+} \mathrm{V}-\mathrm{SVZ}$ NSPCs ipsilateral to the lesion $\left(B, D, F, H\right.$, and $\left.F^{\prime}\right)$ compared to the grossly intact contralateral side $(A, C, E$, and $G)$ and to the non-injured control group (not shown, see Fig. 2). BrdU ${ }^{+}$cells were more pronounced in the lateral [particularly dorsolateral anterior one-third, e.g., ( $B$ and $\left.D\right)$ ] wall of the ventricles adjacent to and oriented (arrows) towards the IC. The density of BrdU ${ }^{+}$cells entering the damaged cortex (epicenter of $\mathrm{HI}$ injury and its penumbra) appeared to be increased [e.g., (B) compared to (A)]; there was also an increase in other adjacent areas: striatum [e.g., (D and F) compared to (C and E)] and cortex [e.g., $\left(F^{\prime}\right)$ ]. Scale bars: $200 \mu \mathrm{m}$ in $(A$ and $E) ; 100 \mu \mathrm{m}$ in $(G) ; 500 \mu \mathrm{m}$ in $\left(\mathrm{F}^{\prime}\right) ; 300 \mu \mathrm{m}$ in (J). NSPCs, neural stem/progenitor cells; HI, hypoxic-ischemic brain injury; OB, olfactory bulb; ROB, right OB; RMS, rostral migratory stream; V-SVZ, ventricular-subventricular zone; LOV, left OB; IC, infarction cavity; LV, left lateral ventricle; RV, right lateral ventricle.

\section{5, $p<0.05$, respectively] (Fig. 2).}

As the migratory route from V-SVZ to OB via the RMS is so well-characterized developmentally programmed destination of migratory V-SVZ NSPCs in the intact brain, ${ }^{6,8,9,28}$ examining it in the context of unilateral HI provides an ideal opportunity to assess the role HI might play in "shifting" migratory patterns. The normal fate for most of the cells born in V-SVZ, particularly the anterior portion ("c-d" in the schematic in Fig. $1 \mathrm{~K}$ and displayed in Fig. 1A-D), is to migrate rostrally along the RMS into the OB ("a-b" in the schematic in Fig. $1 \mathrm{~K}$ and displayed in Fig. 1I and J), where they differentiate into the neu- rons. ${ }^{8,9,28-30}$ Such typical developmental program is evident in the intact left hemisphere [e.g., few BrdU ${ }^{+}$cells surrounding the left lateral ventricle (LV) in Fig. $1 \mathrm{~A}$ and C; many $\mathrm{BrdU}^{+}$cells in left OB (LOB) in Fig. 1I and J].

However, although more cells were actually born in the right V-SVZ ipsilateral to the lesion in response to $\mathrm{HI}$ (Fig. $1 \mathrm{~B}$ and Fig. 2), significantly fewer BrdU ${ }^{+}$cells (about $53 \%$ of uninjured controls) were present in the right RMS (Fig. 2) $1 \mathrm{wk}$ after BrdU injection. In addition, the number of newly-born cells that actually reached the right $\mathrm{OB}(\mathrm{ROB})$ was reduced significantly (about $28 \%$ of uninjured controls and $51 \%$ of that observed con- 
tralateral to the lesion, e.g., ipsilateral ROB compared to contralateral LOB in Fig. 1I, J, and Fig. 2), although the migration route remained anatomically intact. Interestingly, the number of newly-born cells that reached the RMS and OB from the V-SVZ contralateral to the lesion, though certainly much greater than that ipsilateral to the lesion, was also significantly reduced compared to the uninjured control mice (Fig. 2). This suggested that injury may draw cells from even distant regions, affecting the migratory pattern of V-SVZ-derived cells even in the grossly intact contralateral hemisphere. Indeed, the greater number of $\mathrm{BrdU}^{+}$cells in the injured ipsilateral cortex contrasted with, and may also come at the expense of, about $76 \%$ fewer $\mathrm{BrdU}^{+}$cells noted in the contralateral cortex compared to the age-matched uninjured controls (843.8 \pm 77.7 vs. $1117.0 \pm 121.9$, $p<0.05$ ) (Fig. 2), suggesting that NSPCs which normally would have taken up residence in their contiguous cortex ${ }^{31}$ may be diverted towards the lesion as the SVZ $\rightarrow \mathrm{RMS} \rightarrow \mathrm{OB}$ axis was effected.

24 hours after BrdU injection

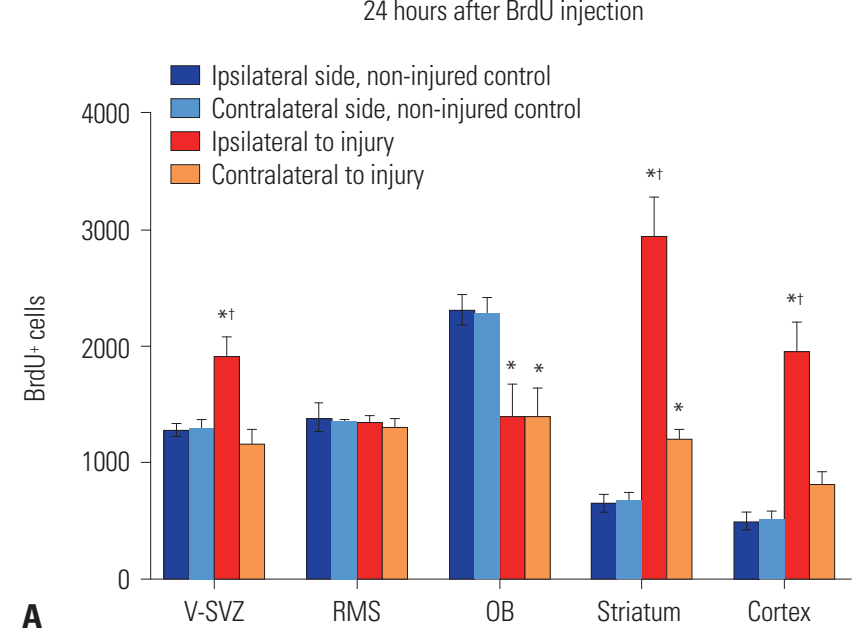

1 week after Brdu injection

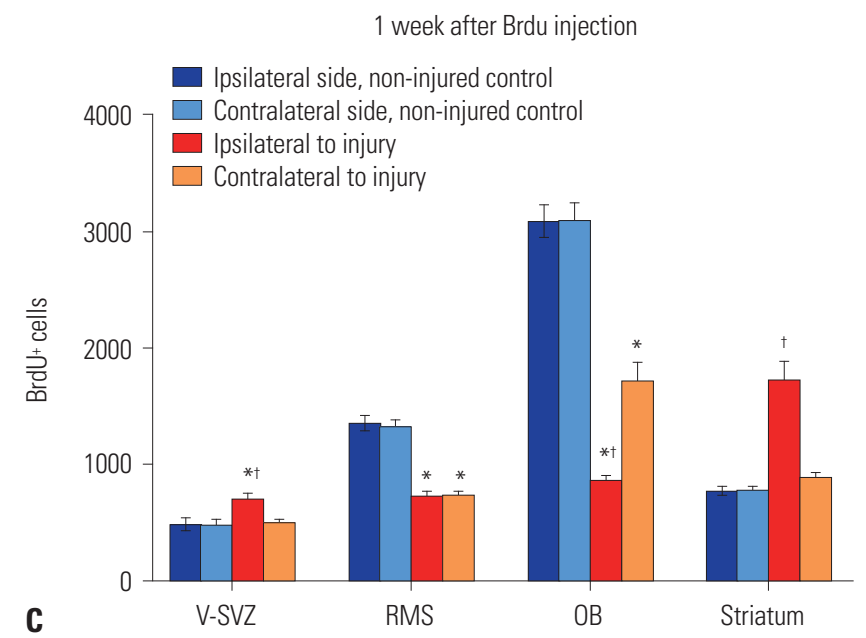

\section{HI promotes the maintenance of cerebral nestin expression}

Consistent with the view that HI may have a broader effect throughout the brain was the pattern of cerebral nestin expression at various times -1 day $(n=5), 1 \mathrm{wk}(\mathrm{n}=7)$, and $3 \mathrm{wk}$ $(\mathrm{n}=5)$ - following unilateral HI, both at the site of injury and in the contralateral intact hemisphere. We analyzed the expression of an intermediate filament protein nestin via IHC, which is known as NSPC and radial glia (embryonic NSPC during CNS development) markers. ${ }^{32-34}$ In contrast to the restricted nestin-immunoreactivity (IR) bordering both lateral ventricles in the intact brain of age-matched control mice on P8 (Fig. $3 \mathrm{~F})$, robust nestin-IR was evident not only in the periventricular regions of both lateral ventricles, but also in the septum, striatum, corpus callosum, external capsule, and cerebral cortices of both hemispheres, particularly at the right cortical infarction site, $24 \mathrm{~h}$ after $\mathrm{HI}$ (Fig. 3A and B). In addition, the density of nestin ${ }^{+}$radial glia fibers with long processes appeared to

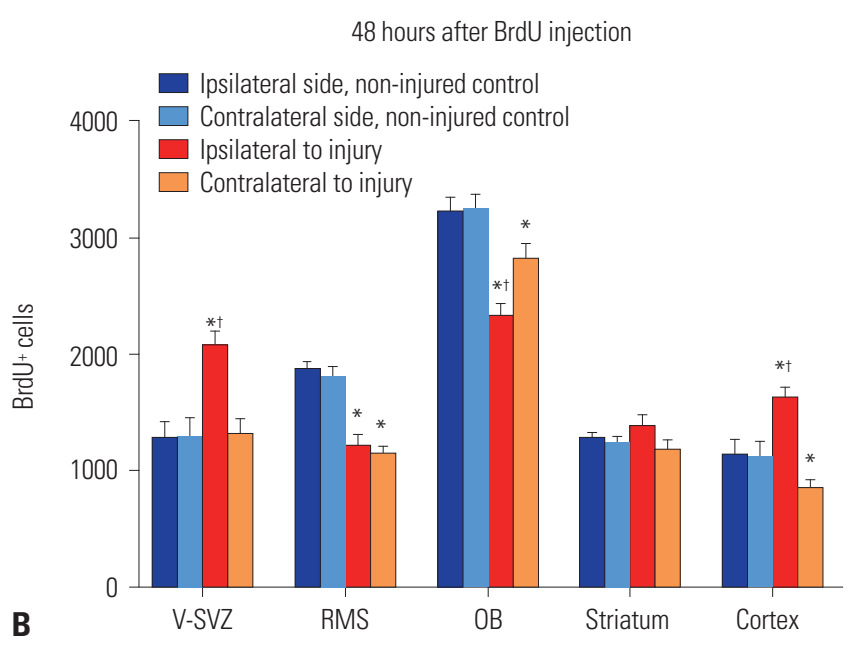

Fig. 2. Density of BrdU-positive newly-born cells following unilateral hypoxic-ischemic brain injury. BrdU ${ }^{+}$cells of $V-S V Z, R M S, O B$, striatum, and cortex in non-injured control and injured animal at $24 \mathrm{~h}(\mathrm{~A}), 48 \mathrm{~h}(\mathrm{~B})$, and 1 week after the final BrdU pulse (C). The number of BrdU ${ }^{+}$cells was not available to count at the cortex at 1 week after BrdU injection. Data represent the means \pm SEM. ${ }^{*} p<0.05$ vs. the corresponding regions in non-injured controls, ${ }^{\dagger} p<0.05$ vs. the contralateral side to the lesion in an injured animal. V-SVZ, ventricular-subventricular zone; RMS, rostral migratory stream; $0 B$, olfactory bulb. 
be highly increased in both hemispheres (arrowheads in Fig. $3 \mathrm{~A}$ and $\mathrm{B}$ ). The robust nestin-IR was maintained in $\mathrm{HI}$ site and cortical penumbral area of ipsilateral hemispheres $1 \mathrm{wk}$ (Fig. 3D) and even $3 \mathrm{wk}$ (data not shown) after HI. However, the nestin-IR in the contralateral hemisphere decreased, except the external capsule, 1 wk after HI (Fig. 3C) and almost disappeared, except the dorsolateral SVZ adjacent to the LV, 3 wk after HI (Fig. 3E). These results suggest that neonatal HI promotes the maintenance of cerebral nestin expression and has the potential to maintain radial glia fibers after injury.

The hypothesis that such appearance of nestin ${ }^{+}$NSPCs or radial glia fibers (even in regions distant from the lesion) might reflect the rapid mobilization or recruitment of NSPCs to regions of cell loss was supported by a further observation of $\mathrm{BrdU}^{+} /$nestin $^{+}$cells around both SVZs (Fig. 4A-C) and within both cortices (Fig. 4D-F). In addition, robust nestin-IR with
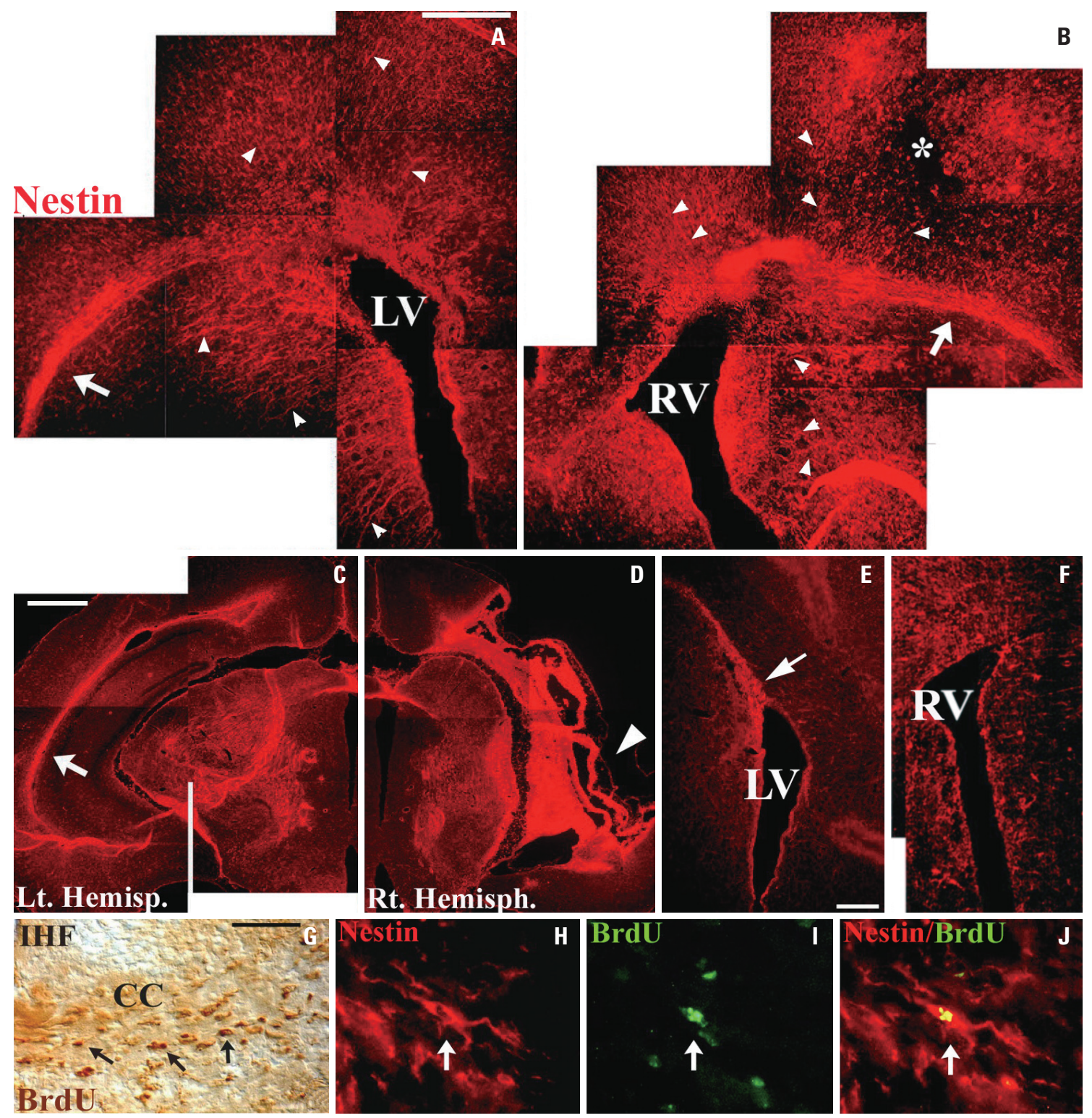

Fig. 3. Unilateral HI promoted the maintenance of cerebral nestin expression. Compared with restricted nestin (red) expression bordering the lateral ventricle in the intact brain of control mice on P8 (F), rapid and robust nestin expression was evident in the periventricular regions, septum, striatum, corpus callosum, external capsules (arrows in $A$ and $B$ ), and cerebral cortices of both ipsilateral right (B) and contralateral left hemispheres (A), particularly at the right cortical infarction site $\left(^{*}\right.$ in B), 1 day after $\mathrm{HI}$. Density of nestin ${ }^{+}$radial glia fibers with long processes appeared to be highly increased in both hemispheres (arrowheads in A and B). While nestin expression in the contralateral hemisphere decreased, except the external capsule (arrow in C), 1 week after $\mathrm{HI}$ and almost disappeared, except the dorsolateral SVZ adjacent the LV (the arrow in E), 3 weeks after HI, the robust nestin expression was maintained in $\mathrm{HI}$ site (arrowhead in D) and cortical penumbral area of the right hemispheres 1 week and even 3 weeks (data not shown) after HI. Many of the BrdU ${ }^{+}$cells (arrows in G, dark brown) in the CC close to IHF showed migration towards HI-injured hemisphere analyzed 1 week after HI. Immunofluorescent labeling showed that migrating BrdU ${ }^{+}$cells (arrow in I, green) in the CC bearing elongated leading processes towards affected hemisphere were dual-labeled with nestin (arrows in H and J, red). Scale bars: $500 \mu \mathrm{m}$ in (A, C, E); $100 \mu \mathrm{m}$ in (G). HI, hypoxic-ischemic brain injury; LV, left lateral ventricle; RV, right lateral ventricle; CC, corpus callosum; IHF, interhemisphere fissue; SVZ, subventricular zone. 
many $\mathrm{BrdU}^{+} /$nestin $^{+}$cells in the corpus callosum bearing elongated leading processes oriented towards the affected hemisphere suggested the migration of NSPCs in response to HI (Fig. $3 \mathrm{G}-\mathrm{J})$. These findings suggest that nestin ${ }^{+}$newly-born $\mathrm{V}-\mathrm{SVZ}$ cells migrate towards adjacent parenchyma and $\mathrm{HI}$ site, and that retained nestin ${ }^{+}$radial glia fibers in response to $\mathrm{HI}$ may provide a scaffold for the migration of V-SVZ-derived neurons and glia toward non-neurogenic brain regions in the postnatal brain. ${ }^{35}$

\section{Differentiation pattern of BrdU-labeled NSPCs in response to $\mathrm{HI}$}

To help determine the differentiation fate in vivo of HI-generated BrdU-labeled NSPCs, particularly in non-neurogenic regions, they were analyzed for their co-expression of neural cell type-specific antigens (Figs. 4 and 5). Over the 3-week period following the final BrdU pulse, many of the cells were induced to proliferate yielded new oligodendrocytes [10.8\% (mean), $6.2 \%$, and $7.4 \%$ at 1, 2, and $3 \mathrm{wk}$, respectively] (Fig. 4P-R and Fig. 5), astrocytes (28.3\%, 15.6\%, and 16.4\%, respectively) (Fig. $4 \mathrm{~S}-\mathrm{U}$ and Fig. 5$)$, and neurons $(4.0 \%, 1.2 \%$, and $1.2 \%$, respectively; Fig. 4G-O and Fig. 5). These new neurons (likely an under-representation given the time course of BrdU pulses) were evident not only in the compromised hemisphere, but in the contralateral hemisphere as well, suggesting the widespread "ripple effect" of signals emanating from even a unilateral lesion. In some experiments designed to assess even longer term survival of BrdU ${ }^{+}$cells, daily ip BrdU pulses for a full week of post-HI were performed. At 2 months after injury, about $1 \%$ of $\mathrm{BrdU}^{+}$cells were $\mathrm{NF}^{+}$- not significantly diminished from this value at 3 weeks - suggesting permanence of the new neu-

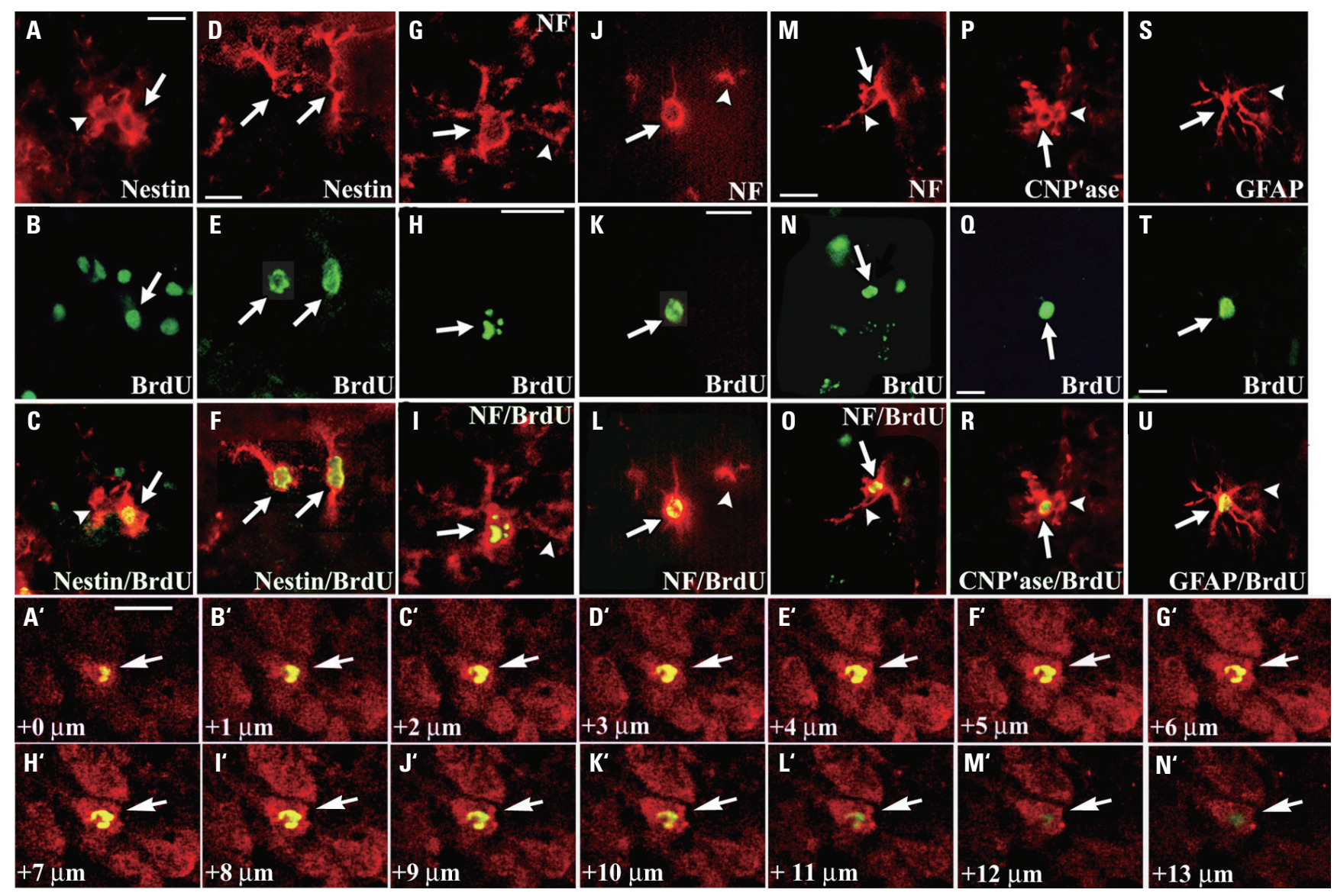

Fig. 4. Differentiation pattern of BrdU-labeled NSPCs in response to $\mathrm{HI}$. A day after unilateral $\mathrm{HI}$ and the final BrdU pulse, many cells around the $\mathrm{V}$ SVZ $(A-C)$ and in the cortex (D-F) of both hemispheres showed co-localization of both anti-nestin $(A, D)$ (red) and anti-BrdU (B, E) (green) immunoreactivity (arrows), appreciated in merged images (C, F, respectively). One-to-three weeks after $\mathrm{HI}$, many of the BrdU ${ }^{+}$cells [arrows in $(\mathrm{H}, \mathrm{K}, \mathrm{N}, \mathrm{Q}, \mathrm{T})$ ] had differentiated into new neurons $(\mathrm{G}-\mathrm{O})$, oligodendrocytes $(\mathrm{P}-\mathrm{R})$, and astrocytes $(\mathrm{S}-\mathrm{U})$ predominantly in the injured hemisphere, supplementing non-BrdU ${ }^{+}$ [arrowheads in (G, I, J, L, M, O, P, R, S, U)] of the respective cell type with which they seamlessly intermixed, and were often directly juxtaposed. The new neurons, recognized here as $\mathrm{NF}^{+}($red) cells [arrows in $(\mathrm{G}, \mathrm{J}, \mathrm{M})$ and under the dual-wavelength filter in $(\mathrm{I}, \mathrm{L}, \mathrm{O})$ ], were present in the neocortexpredominantly ipsilateral [arrows in (G-I)] but even contralateral to the lesion [arrows in (J-L)] —and in the ipsilateral hippocampal CA1 area [arrows in (M-O)]_all classically regarded as non-neurogenic regions. The oligodendrocyte marker CNP'ase and the astrocyte marker GFAP were employed in (P) [and under the dual filter in (R)] and (S) [and under the dual filter in (U)], respectively. Arrowheads in (A, C) indicate cellular processes of Nestin ${ }^{+}$I BrdU immature cells. Confocal images showed that a BrdU ${ }^{+}$cell (green) (arrows) colocalized with the mature neuronal marker NeuN (red) under the dual-wavelength filter in $\left(A^{\prime}-N^{\prime}\right)$. Scale bars: $10 \mu \mathrm{m}$ in $\left(A, D, H, K, M, A^{\prime}\right) ; 5 \mu \mathrm{m}$ in $(0, T)$. NSPCs, neural stem/progenitor cells; HI, hypoxic-ischemic brain injury; V-SVZ, ventricular-subventricular zone. 
rons. Notably, these analyses were performed caudal to the OBs and rostral to the dentate gyrus of hippocampus to prevent confusion with neurons routinely generated locally in these neurogenic regions. ${ }^{5-14,16}$ Following HI, neurons are the neural cell type most susceptible to elimination, yet they are the very cells deemed as incapable of being renewed in non-neurogenic regions. Given such expectations, the actual numbers were somewhat less consequential than the fact of observing any new neurons in areas that were heretofore regarded as harboring no new neurons, and were considered representative of most of the postnatal brain. The proportion of endogenous NSPCs differentiating into various neural cell types-including the proportion remaining immature and undifferentiated-was consistent with prior studies quantifying the phenotype of proliferative cells following exogenous mitogen/growth factor infusions. ${ }^{36-38}$

\section{Tracking of LacZ-expressing V-SVZ NSPCs in response to $\mathrm{HI}$}

As a complement to BrdU labeling and to more rigorously track the fate of these newly proliferative HI-responsive V-SVZ NSPCs (as well as to selectively label periventricular cells independent of local cortical parenchymal progenitors), mitotic cells were identified by their incorporation of a retroviral provirus encoding lacZ following infection by a retrovirus vector ${ }^{21}$ injected into the ventricles. A cell that was in S-phase at the time of exposure to the retrovirus indicated LacZ expression; therefore, LacZ expression, revealed by an antibody to $\beta \mathrm{gal}$, provided a direct unambiguous tag for detecting, tracking, and determining the subsequent fate of that cell. The mice were sacrificed at least $1 \mathrm{wk}$ after retrovirus injection into both lateral ventricles of mice being subjected to unilateral $\mathrm{HI}(\mathrm{n}=5)$ (Fig. 6). In response to $\mathrm{HI}, \mathrm{\beta gal}^{+} \mathrm{V}$-SVZ cells migrated into the adjacent striatum (Fig. 6A) and hippocampus, into the cortex ipsilateral to the lesion (Fig. 6D), and into the cortical penumbra (Fig. 6J). In addition, some LacZ-labeled V-SVZ (often in groups $^{29,30}$ ) also migrated into the cortex (Fig. 6G) and overlying hippocampal CAl area (Fig. 6M). Providing a broader overview under low magnification, LacZ-labeled V-SVZ NSPCs following severe HI showed a robust radiating migratory pattern towards the overlying hippocampus and neocortex (Fig. 6P and Q). Confirming the observation noted in Fig. 6G-O, a subpopulation of the newly proliferative and migratory $\beta \mathrm{gal}^{+}$cells now expressed mature neuronal marker (e.g., NeuN) in all of these non-neurogenic regions (Fig. 6C, F, I, L, O, and Q), suggesting de novo neurogenesis. The $\mathrm{NeuN}^{+}$neurons were suggested to be active, integrated, and activatable in concert with other regional neurons, based on their immunohistochemically detectable upregulation and expression of c-fos and synapsin in the living, behaving animal (Fig. 6R-Z), e.g., in cortex including the infarcted area (Fig. 6R-T, X-Z) and hippocampus (CA3) where $59.6 \pm 3.2 \%$ and $25.2 \pm 4.2 \%$ of $\mathrm{LacZ}^{+}$cells were dual immunoreactive with NeuN and nestin, respectively (Fig. 6U-W).

\section{Tracking of NeuroD1/GFP-expressing V-SVZ NSPCs in response to $\mathrm{HI}$}

NeuroD1 is a basic helix-loop-helix (bHLH) transcriptional factor that is highly expressed in the developing neurons of peripheral and CNS, supporting its role as a neuronal differentiation factor. NeuroD1 may contribute to multiple levels of neural development; nevertheless, it is believed that NeuroD1 mainly plays important roles in the terminal differentiation of postmitotic neuronal cells. ${ }^{39}$ Therefore, we asked if NeuroD1transduced V-SVZ NSPCs could enhance neuronal differentiation of internal pool of NSPCs and provide greater numbers of new neurons in non-neurogenic brain regions in response to HI. Retroviral vectors encoding NeuroD1/GFP and GFP were injected into both lateral ventricles of mice being subjected to unilateral $\mathrm{HI}$ ( $\mathrm{n}=5$ for each group) and analyzed at least $1-2$ wk later (Fig. 7). In response to $\mathrm{HI}, \mathrm{NeuroD1}^{+} / \mathrm{GFP}^{+}$mitotic VSVZ NSPCs migrated into the adjacent striatum, subcortex, and cortical penumbra ipsilateral to the lesion (Fig. 7A, A' B, B'), and along the external capsule and corpus callosum (Fig. 7A, A", and B). The majority of newly-born and migratory GFP ${ }^{+}$

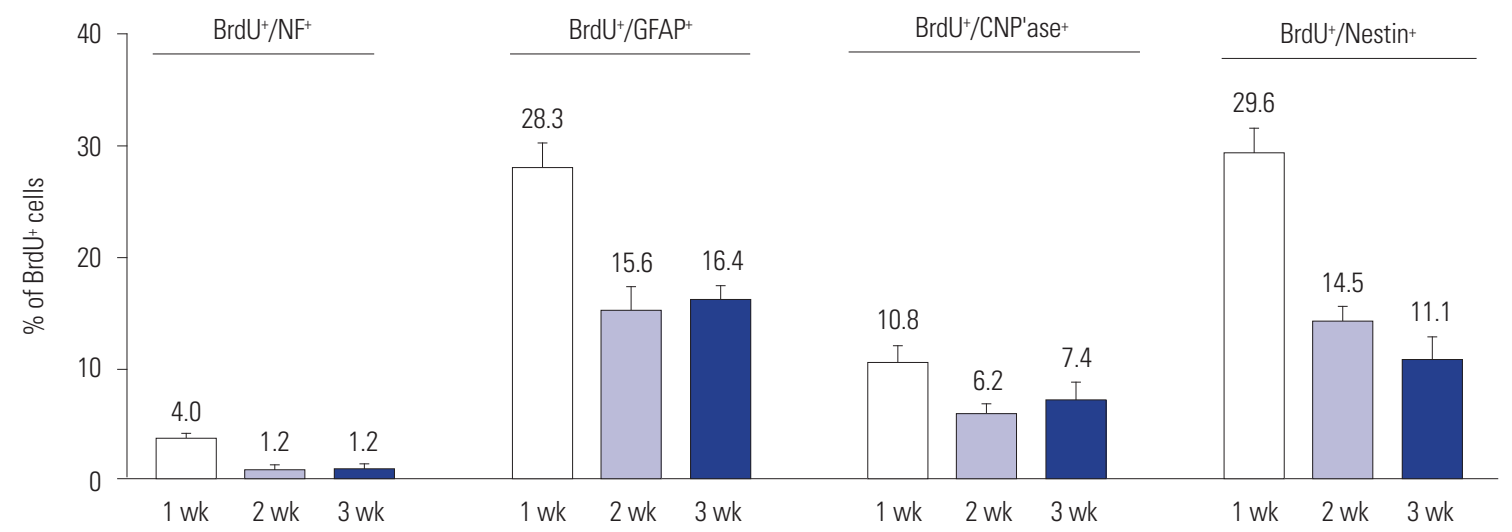

Fig. 5. Cellular differentiation patterns of $\mathrm{HI}$-generated BrdU $\mathrm{Bu}^{+}$newly-born cells in non-neurogenic regions. Counts represent the means and SEM of the sums of every 6th 15- $\mu \mathrm{m}$ coronal section extending caudally from the rostral tip of the lateral ventricle for the entire expanse of both cerebral cortices (ipsilateral and contralateral to HI). HI, hypoxic-ischemic brain injury. 

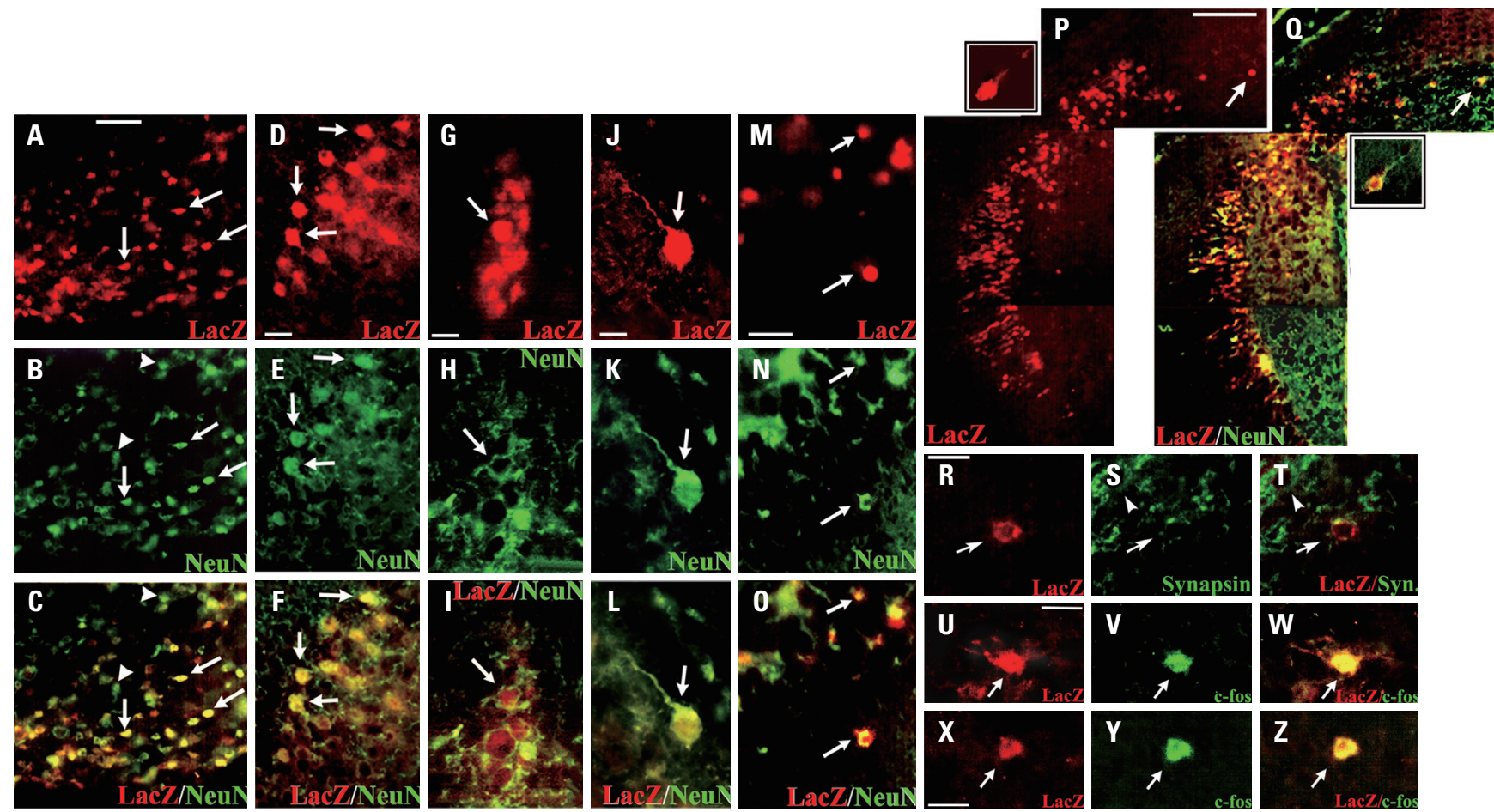

Fig. 6. Immunostaining of retrovirally-infected endogenous mitotic V-SVZ NSPCs with LacZ following HI. In response to $\mathrm{HI}_{\text {, LacZ-expressing } \beta \text { gal }}{ }^{+}$ cells (red) migrated widely, including into the striatum (A), the cortex ipsilateral to the lesion (D), and the cortical penumbra of the infarct (J). Some of these $\beta \mathrm{gal}^{+}$cells $(A, D, J)$ (red, arrows) expressed the mature neuronal marker NeuN (B, E, K, respectively) (green, arrows) with co-localization of both antibodies visualized under a dual filter (C, F, L, respectively) (arrows), suggesting de novo neurogenesis. Arrowheads in (B, C) indicate neurons that were not the progeny of retrovirus-infected NSPCs. In the grossly intact contralateral hemisphere, there was also evidence for the migration and differentiation into $\mathrm{NeuN}^{+}$neurons of some $\beta$ gal ${ }^{+}$cells in the neocortex (G-I) (arrows) and hippocampal CA1 region (M-0) (arrows) in response to severe $\mathrm{HI}$. These phenomena were further illustrated by a low magnification view of the cerebral cortex and hippocampus, in which a significant number of $\beta \mathrm{gal}{ }^{+}$V-SVZ NSPCs that migrated to these regions (P) (red) differentiated into NeuN ${ }^{+}$neurons ( $(0)$ (yellow/orange under a dual filter). Insets in (P) and $(0)$ showed the representative $\beta$ gal ${ }^{+}$cell indicated by the arrow in $(P)$ and $(0)$, respectively, further enlarged to illustrate the typical morphology of a newly-born neuron derived from a labeled V-SVZ cell that had migrated to the neocortex following injury. (R-Z) The representative $\beta g a{ }^{+}{ }^{~ c e l l s ~ i n ~ t h o s e ~}$ regions [red cells with arrows in $(\mathrm{R})$ and $(\mathrm{U}, \mathrm{X})$ ] were immunoreactive to an anti-synapsin 1 [green cell with the arrow in $(\mathrm{S})$ ] and c-fos nuclear [green cells with arrows in $(V, Y)$ ] antibodies, respectively, and visualized under a dual filter [cells with arrows in (T, W, Z)]. Scale bars: $50 \mu \mathrm{m}$ in $A ; 5 \mu \mathrm{m}$ in $D, G$, $\mathrm{J} ; 10 \mu \mathrm{m}$ in M, R, U, X; $100 \mu \mathrm{m}$ in P. V-SVZ, ventricular-subventricular zone; NSPCs, neural stem/progenitor cells; HI, hypoxic-ischemic brain injury.

cells transduced with a retrovirus encoding GFP expressed astrocyte marker GFAP (65.1 $\pm 5.6 \%)$ (Fig. 7C-E") and the oligodendroglial progenitor marker Olig2 (22.4 $\pm 3.8 \%)$ (Fig. 7F-H'), whereas relatively few expressed early neuronal marker DCX $(11.3 \pm 2.5 \%)$ in the striatum and cortical penumbral area (Fig. 7I-K'). In contrast, most of the newly-born and migratory $\mathrm{GFP}^{+}$ cells transduced with a retrovirus encoding NeuroD1/GFP did not express GFAP or Olig2, but expressed early neuronal marker DCX or mature neuronal marker NeuN $(95.1 \pm 7.4 \%)$ in all of these non-neurogenic brain regions (Fig. 7L-X), suggesting enhanced neurogenesis. In addition, very few of $\mathrm{GFP}^{+}$cells (1.3 $\pm 0.7 \%)$ expressed nestin (data not shown).

\section{DISCUSSION}

This study sought to elucidate the brain's intrinsic response to $\mathrm{HI}$, particularly as it involves an endogenous V-SVZ NSPC pool and specifically in areas that are designated "non-neurogenic" and hence non-regenerative. Our findings suggest that neo- natal $\mathrm{HI}$ alters developmental programs and does so towards the goal of repopulation and self-repair, allocating new cells to the regions of greatest need; during acute phases of neurodegeneration, many factors, such as morphogens, growth factors, neurotrophic factors, erythropoietin, and microRNAs, are elaborated to which endogenous NSPCs may respond to promote the establishment of new neurons, even within non-neurogenic regions of the postnatal brain. ${ }^{17,40}$ Some of these newlyborn neurons, while generated from V-SVZ NSPCs, appear to be targeted specifically to damaged, neuron-deficient regions by redirecting otherwise stereotypical migratory patterns. Such observations may attest to an under-appreciated degree of plasticity and resilience in the mammalian CNS, even beyond the classical periods and regions of developmental malleability. The CNS may, indeed, spontaneously attempt to repair itself with its own endogenous pool of NSPCs, but that supply may simply be insufficient either in number or in factors regulating proliferation, migration, and differentiation in the context of the most destructive injuries. Therefore, the net impact of the production of new nerve cells may be limited. It is plau- 
sible that this type of homeostatic response occurs routinely at a marginally detectable level, and is effective under most circumstances (where CNS insults are modest-e.g., from infections, toxins, minor trauma) in preventing such events from coming to clinical attention. However, when the damage is massive, the system - invoked but inadequate-is "overwhelmed."
Consequently, there is no apparent recovery, although endogenous NSPCs have responded in a "reparative" fashion to signals directing them towards repopulation of the damaged area. Nevertheless, this does not negate the inherent plasticity of CNS nor the potential for augmenting this response. Therefore, the relationship between the severity of $\mathrm{HI}$ and NSPC response re-
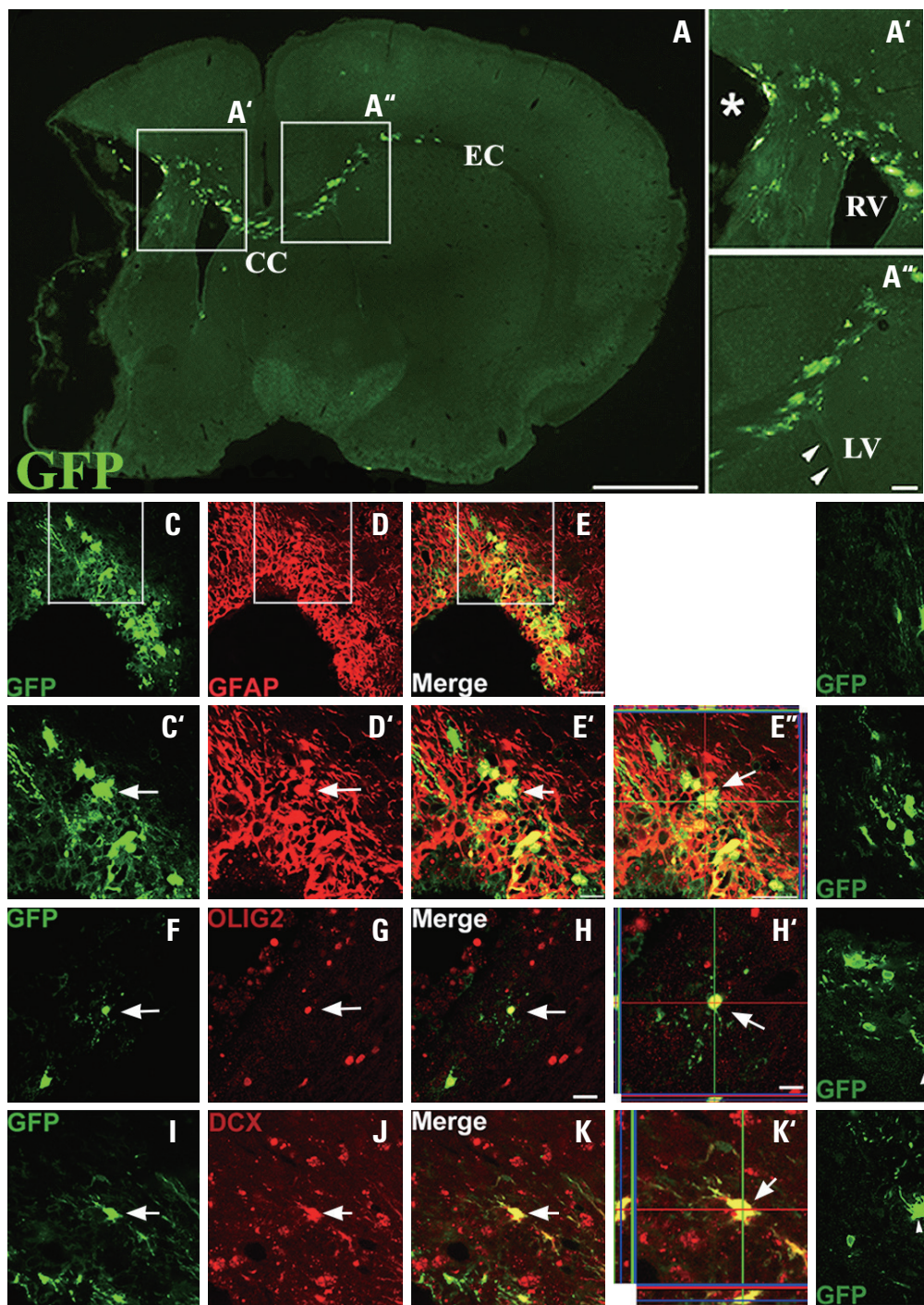
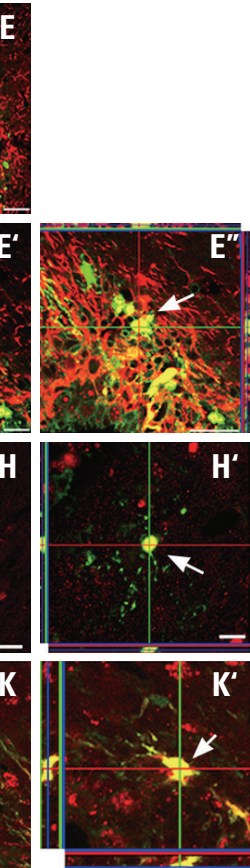
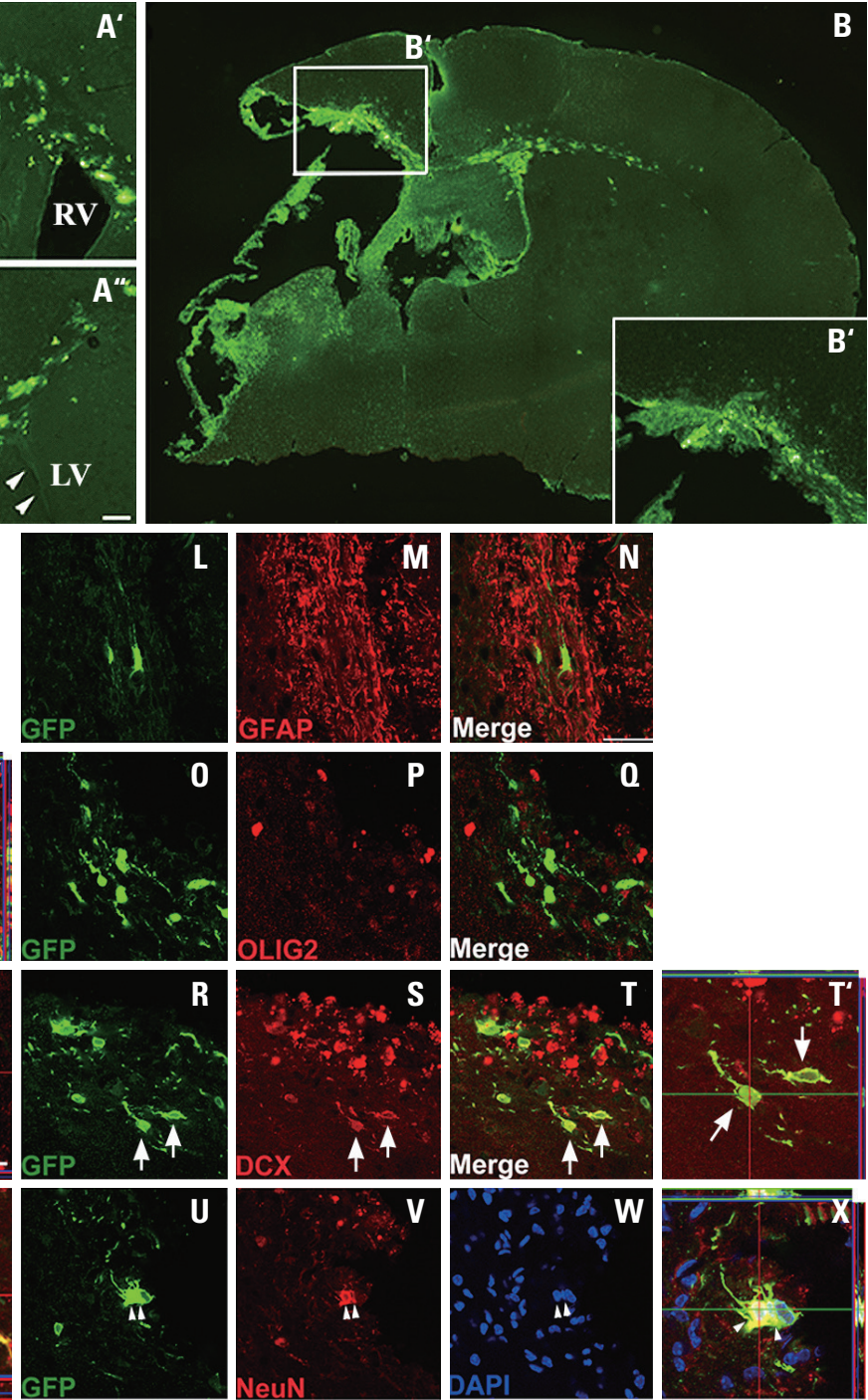

Fig. 7. Immunostaining of retrovirally-infected endogenous mitotic V-SVZ NSPCs with NeuroD1/GFP and GFP following HI. In response to HI, NeuroD1/GFP-expressing $\mathrm{GFP}^{+}$cells (green) migrated into the adjacent striatum, subcortex, and cortical penumbra ipsilateral to the lesion (A, $\left.A^{\prime}, B_{1} B^{\prime}\right)$, and along the $E C$ and $C C\left(A, A^{\prime \prime}, B\right)$. The boxed areas in $A$ and $B$ are shown at high magnification in $A^{\prime}, A^{\prime \prime}$ and $B^{\prime}$. The asterisk in $A^{\prime}$ and arrowheads in $A^{\prime \prime}$ indicates the infarction cavity and $L V$, respectively $\left(C-K^{\prime}\right)$. Many of the newly-born and migratory $\mathrm{GFP}^{+}$cells $\left(C, C^{\prime}\right)$ transduced with a retrovirus encoding GFP expressed astrocyte marker GFAP (D, D', respectively) (red) with co-localization of both antibodies visualized under a dual filter (E, E', respectively) (yellow or orange) in the cortical penumbral area. Boxed regions in (C-E) are magnified in $\left(C^{\prime}-E^{\prime}\right)$, respectively. Arrows in ( $\left.C^{\prime}-E^{\prime \prime}\right)$ indicate duallabeled cells (F-H). Some of newly-born GFP ${ }^{+}$cells (F) expressed the oligodendrocyte progenitor marker Olig2 (G) (red) with co-localization of both antibodies visualized under a dual filter (H). Arrows in (F-H) indicate dual-labeled cells. (I-K) A few of newly-born GFP ${ }^{+}$cells (I) expressed early neuronal marker DCX (J) (red) with co-localization of both antibodies visualized under a dual filter (K). Confocal images showed that GFP' ${ }^{+}$cells (arrows in $\mathrm{E}^{\prime \prime}, \mathrm{H}^{\prime}$ and $\mathrm{K}^{\prime}$ ) colocalized with differentiation markers under a dual filter (yellow or orange) (L-X). In contrast, most of the newly-born and migratory GFP ${ }^{+}$cells [arrows and arrowheads in (R) and (U), respectively] transduced with a retrovirus encoding NeuroD1/GFP expressed early neuronal marker DCX [arrows in (S)] (red) or mature neuronal marker NeuN [arrowheads in (V)] (red) with co-localization of both antibodies visualized under a dual filter [arrows in (T)] (yellow or orange) in the striatum and cortical penumbral area. DAPI cells [arrowheads in (W)] (blue) indicate dual-labeled cells. Confocal images showed that $\mathrm{GFP}^{+}$cells [arrows and arrowheads in $\left(\mathrm{T}^{\prime}\right)$ and $(X)$, respectively] colocalized with neuronal markers under a dual filter (yellow or orange). However, GFP ${ }^{+}$cells (L, O) did not express GFAP or Olig2 (M, N, P, O). Scale bars: $500 \mu \mathrm{m}$ in (A); $20 \mu \mathrm{m}$ in (H', N) $10 \mu \mathrm{m}$ in (A", E, E", H). V-SVZ, ventricularsubventricular zone; NSPCs, neural stem/progenitor cells; HI, hypoxic-ischemic brain injury; EC, external capsule; CC, corpus callosum; LV, left lateral ventricle; $\mathrm{RV}$, right lateral ventricle. 
mains to be explored. The prediction of NSPC response based on the level of severity of $\mathrm{HI}$ is an important issue that should be further investigated.

While it is clear that newly-born brain cells are being produced in response to HI, data compiled to date suggest that the long-term survival of migrated neuroblasts or newly-born neurons in the injured area is not supported. ${ }^{41-43}$ The reasons for the death of newly-born neurons remain elusive and may be due to the inhospitable post-HI environment. HI initiates an inflammatory cascade, such as microglial activation, immune cells infiltration, and the release of toxic proinflammatory molecules. ${ }^{44}$ Microglial activation, proinflammatory factors, and circulating monocytes associated with inflammation not only lead to neuron death but also affect the neurogenesis and survival of newly-born neurons. ${ }^{40}$ In addition, some studies have indicated that SVZ-derived migratory NSPCs differentiate into reactive astrocytes and contribute to astrocyte scar formation after stroke. ${ }^{45,46}$ While the role of astrogliosis after stroke or $\mathrm{HI}$ is still elusive and requires further investigation, the modulation of pathologic environment after $\mathrm{HI}$ by anti-inflammatory or neurogenic factors results in substantial repair of neural tissue. ${ }^{47,48}$

Radial glial (RG) cells are embryonic neural stem cells expressing nestin, GFAP, and astrocyte-specific glutamate transporter that extend apical long processes to the pial surface from their soma, which is located in the ventricular zone.$^{33} \mathrm{RG}$ cells are not only stem cells and progenitors, but during brain development they also provide a scaffold along which newly generated immature neurons migrate from the periventricular zone into the neocortex and to subcortical structures. In the late fetal period in the human brain, and in the first postnatal week in the rodent brain, the RG fibers collapse, transform into astrocytes or ependymal cells, and normally disappear soon after birth. ${ }^{49}$ However, this study showed that signals generated in HI elicited robust cerebral nestin expression, and the density of nestin $^{+}$radial glia fibers with long processes appeared to be highly increased in both hemispheres. Moreover, the robust nestinIR was maintained in the lesioned and cortical penumbral areas of ipsilateral hemispheres, even more than 3 weeks after HI. These findings suggest that retained nestin ${ }^{+}$radial glia fibers in response to HI may provide a scaffold for the widespread migration of V-SVZ-derived neurons toward non-neurogenic brain regions in the postnatal brain. Similarly, earlier studies reported an increase in cells expressing RG markers after chronic hypoxia in immature rats, and demonstrated the role of RG cells in both neurogenesis and migration. ${ }^{50,51}$ A recent study also showed that RG fiber persisted in neonatal mouse brain after cryogenic injury and acted as a scaffold for the migration of V-SVZ-derived neuroblasts to the lesion site, thereby enhancing neuronal regeneration and functional recovery from neonatal brain injuries..$^{35}$

Whereas there has been a great increase of studies observing neuronal replacement after neonatal HI, there have been fewer studies assessing the extent of oligodendroglial replace- ment. This study, along with other reports, ${ }^{52-54}$ documented an increase in the number of newly generated oligodendrocytes in the damaged hemispheres and suggested that these newlyborn oligodendrocytes were produced by V-SVZ NSPCs. However, none of these studies clearly established whether these newly-born oligodendrocytes proceeded to differentiate into mature myelin-producing cells. In this study, significant astrogliosis was observed after $\mathrm{HI}$, along with an increase in $\mathrm{BrdU}^{+}$/ $\mathrm{GFAP}^{+}$cells. It is well-known that reactive astrocytes produce extracellular matrix components, such as hyaluronic acid and chondroitin sulfate proteoglycan, that inhibit oligodendrocyte differentiation. ${ }^{55,56}$ In addition, astrocytes produce numerous cytokines, including fibroblast growth factors, WNT ligands, endothelin-1, and Notch ligands, that inhibit oligodendrocyte progenitor cell maturation. ${ }^{17}$ There is also an alternative explanation for the lack of myelination depending on SVZ cell specification. ${ }^{57,58}$ However, further research is critically needed to facilitate the differentiation into mature, myelin-producing cells from V-SVZ NSPC-derived oligodendrocytes in HI.

Identifying the cues that promote the movement and differentiation of this endogenous pool of NSPCs during their normal, developmentally-appropriate migratory course $\mathrm{e}^{28-30,59,60}$ and, as we observed here, during their confrontation with neurodegeneration, may allow those factors to be provided therapeutically at even more optimal, sustained levels, over broader periods and terrain. In fact, multiple cytokines, such as Delta/ Notch-1, erythropoietin, interleukin-6, leukemia inhibitory factors (LIF), transforming growth factor, and vascular endothelial growth factor (VEGF), were reported to be elaborated to which endogenous NSPCs respond to change in their proliferation, migration, and differentiation patterns after neonatal HI. In addition, the treatment of erythropoietin, brain-derived neurotrophic factor, epidermal growth factor, VEGF, LIF, hyperbaric oxygen, or hypothermia has been shown to attenuate $\mathrm{HI}$ by modulating the behavior of endogenous NSPCs. ${ }^{17,40}$ Lastly, we have demonstrated here that neurogenic transcriptional factor NeuroDl can efficiently convert V-SNZ NSPCs to neurons, providing a new target for cellular conversion strategies aimed at enhancing neurogenesis. Therefore, augmenting the endogenous NSPC population with exogenous neural stem cells,${ }^{40}$ factors, and/or providing adequate synaptic neighbors and guidance cues for connectivity and trophic support may enable more significant recovery.

BrdU labeling for mitotic cells is still the most commonly used of the thymidine analogues, and much work on this subject has been done in mice. However, BrdU inhibited the expansion of NSPCs, increased cell death, and repressed neuronal and oligodendroglial differentiation ${ }^{61}$ Although BrdU does obviously label dividing cells, BrdU positivity may be due to attempts of cells to repair themselves or a sign of cell death (apoptosis). In addition, BrdU has been well-known to have detrimental effects on chromosomes and DNA stability, as well as the cell cycle, cell differentiation, and survival.$^{62}$ Besides the 
toxicity of BrdU and caveats concerning its utility, BrdU labeling, particularly at the epicenter of HI, can be hard to interpret due to the reliance on immunodetection in the injury setting, where significant labeling issues can arise. In addition, BrdU is subject to dilution effects, where the absence of labeling or decreased labeling over time can be misinterpreted. Therefore, we also utilized a retroviral vector to label mitotic NSPCs and their progeny, a technique that is not affected by the number of cell divisions. Another advantage of using a retroviral approach is the ability to direct the location of injection into VSVZ NSPCs. Gene transfer mediated by replication-incompetent retroviral vectors has played an important role in developmental studies, particularly in revealing lineage relationships among different cell types. Replication-incompetent retroviral vectors have also been used for gain-of-function studies to explore the molecular mechanisms underlying cell differentiation in neural tissues of mice. The greatest advantage of this approach is that it can reveal cell-autonomous effects of a transgene, such as NeuroD1, on cell differentiation without disrupting the overall context of development. ${ }^{63}$ However, gamma retroviral vectors have a propensity to integrate near regulatory regions of active genes. The activity of promoter/enhancer elements within the vector long terminal repeats (LTRs) or aberrant splicing events can lead to the activation of genes flanking the integration site. This is commonly referred to as insertional mutagenesis. If the genes near the integration sites are proto-oncogenes, it may lead to increased proliferation of clonal populations of cells. In addition, a number of studies have shown that the promoter regions of gamma retroviral vectors may be subject to epigenetic silencing, which has been associated with DNA methylation of CpG sequences. Such silencing events gradually reduce the expression of transgenes, such as LacZ, GFP, or NeuroD1, under the control of both viral LTR and internal promoters. ${ }^{64}$ Taken together, it is difficult to find a single method to accurately and dynamically track the behaviors of endogenous NSPCs in response to HI. Therefore, more sophisticated measures including the use of genetic mouse models or live molecular imaging would be required to avoid the common mistake of demonstrating the behaviors of endogenous NSPCs in HI.

\section{ACKNOWLEDGEMENTS}

This study was supported by a faculty research grant of Yonsei University College of Medicine (6-2019-0096) and Bio \& Medical Technology Development Program of the National Research Foundation (NRF) funded by the Korean government (MSIT) (No. NRF-2019M3A9H1032791).

\section{AUTHOR CONTRIBUTIONS}

Conceptualization: Kook In Park. Data curation: Jeong Eun Shin, Haejin Lee, and Kook In Park. Formal analysis: Jeong Eun Shin.
Funding acquisition: Jeong Eun Shin and Kook In Park. Investigation: Jeong Eun Shin, Haejin Lee, Kwangsoo Jung, Miri Kim, Kyujin Hwang, and Il-Sun Kim. Methodology: Haejin Lee, Kwangsoo Jung, Miri Kim, Kyujin Hwang, and Kwang-Il Lim. Project administration: Kook In Park. Resources: Kook In Park. Supervision: Kook In Park. Validation: Joohee Lim, Jungho Han, Kook In Park. Visualization: Jeong Eun Shin. Writing_original draft: Jeong Eun Shin and Kook In Park. Writingreview \& editing: Kook In Park. Approval of final manuscript: all authors.

\section{ORCID iDs}

Jeong Eun Shin https://orcid.org/0000-0002-4376-8541 Haejin Lee https://orcid.org/0000-0003-1455-4189 Kwangsoo Jung https://orcid.org/0000-0001-7365-7247 Miri Kim https://orcid.org/0000-0002-0380-1677 Kyujin Hwang https://orcid.org/0000-0001-5193-5154 Jungho Han https://orcid.org/0000-0001-6661-8127 Joohee Lim https://orcid.org/0000-0003-4376-6607 Il-Sun Kim https://orcid.org/0000-0003-4033-4323 Kwang-Il Lim https://orcid.org/0000-0002-1895-2080 Kook In Park https://orcid.org/0000-0001-8499-9293

\section{REFERENCES}

1. Ferriero DM. Neonatal brain injury. N Engl J Med 2004;351:198595.

2. Volpe JJ. Neonatal encephalopathy: an inadequate term for hypoxic-ischemic encephalopathy. Ann Neurol 2012;72:156-66.

3. Azzopardi DV, Strohm B, Edwards AD, Dyet L, Halliday HL, Juszczak E, et al. Moderate hypothermia to treat perinatal asphyxial encephalopathy. N Engl J Med 2009;361:1349-58.

4. Shankaran S, Pappas A, McDonald SA, Vohr BR, Hintz SR, Yolton $\mathrm{K}$, et al. Childhood outcomes after hypothermia for neonatal encephalopathy. N Engl J Med 2012;366:2085-92.

5. Ramon y Cajal S. Degeneration and regeneration of the nervous system. Oxford: Clarendon Press; 1928.

6. Altman J. Autoradiographic and histological studies of postnatal neurogenesis. IV. Cell proliferation and migration in the anterior forebrain, with special reference to persisting neurogenesis in the olfactory bulb. J Comp Neurol 1969;137:433-57.

7. Altman J, Das GD. Autoradiographic and histological evidence of postnatal hippocampal neurogenesis in rats. J Comp Neurol 1965; 124:319-35.

8. Goldman SA, Luskin MB. Strategies utilized by migrating neurons of the postnatal vertebrate forebrain. Trends Neurosci 1998;21: 107-13.

9. Lois C, Alvarez-Buylla A. Proliferating subventricular zone cells in the adult mammalian forebrain can differentiate into neurons and glia. Proc Natl Acad Sci U S A 1993;90:2074-7.

10. Kornack DR, Rakic P. Continuation of neurogenesis in the hippocampus of the adult macaque monkey. Proc Natl Acad Sci U S A 1999;96:5768-73.

11. Gould E, Reeves AJ, Fallah M, Tanapat P, Gross CG, Fuchs E. Hippocampal neurogenesis in adult Old World primates. Proc Natl Acad Sci U S A 1999;96:5263-7.

12. Cameron HA, McKay RD. Restoring production of hippocampal neurons in old age. Nat Neurosci 1999;2:894-7.

13. Eriksson PS, Perfilieva E, Björk-Eriksson T, Alborn AM, Nordborg C, Peterson DA, et al. Neurogenesis in the adult human hippocampus. Nat Med 1998;4:1313-7.

14. Gould E, Beylin A, Tanapat P, Reeves A, Shors TJ. Learning en- 
hances adult neurogenesis in the hippocampal formation. Nat Neurosci 1999;2:260-5.

15. Lim DA, Huang Y, Alvarez-Buylla A. Adult subventricular zone and olfactory bulb neurogenesis. Cold Spring Harb Perspect Biol 2008;52:175.

16. Kempermann G, Gage FH, Aigner L, Song H, Curtis MA, Thuret S, et al. Human adult neurogenesis: evidence and remaining questions. Cell Stem Cell 2018;23:25-30.

17. Niimi Y, Levison SW. Pediatric brain repair from endogenous neural stem cells of the subventricular zone. Pediatr Res 2018;83: 385-96.

18. Paredes MF, James D, Gil-Perotin S, Kim H, Cotter JA, Ng C, et al. Extensive migration of young neurons into the infant human frontal lobe. Science 2016;354:aaf7073.

19. Sanai N, Nguyen T, Ihrie RA, Mirzadeh Z, Tsai HH, Wong M, et al. Corridors of migrating neurons in the human brain and their decline during infancy. Nature 2011;478:382-6.

20. Rice JE, Vannucci RC, Brierley JB. The influence of immaturity on hypoxic-ischemic brain damage in the rat. Ann Neurol 1981;9: 131-41.

21. Price J, Turner D, Cepko C. Lineage analysis in the vertebrate nervous system by retrovirus-mediated gene transfer. Proc Natl Acad Sci U S A 1987;84:156-60.

22. Flax JD, Aurora S, Yang C, Simonin C, Wills AM, Billinghurst LL, et al. Engraftable human neural stem cells respond to developmental cues, replace neurons, and express foreign genes. Nat Biotechnol 1998;16:1033-9.

23. Lim KI, Klimczak R, Yu JH, Schaffer DV. Specific insertions of zinc finger domains into Gag-Pol yield engineered retroviral vectors with selective integration properties. Proc Natl Acad Sci U S A 2010; 107:12475-80.

24. Nam JS, Lee JE, Lee KH, Yang Y, Kim SH, Bae GU, et al. Shifting retroviral vector integrations away from transcriptional start sites via DNA-binding protein domain insertion into integrase. Mol Ther Methods Clin Dev 2018;12:58-70.

25. Shin JE, Jung K, Kim M, Hwang K, Lee H, Kim IS, et al. Brain and spinal cord injury repair by implantation of human neural progenitor cells seeded onto polymer scaffolds. Exp Mol Med 2018;50:39.

26. Kuhn HG, Dickinson-Anson H, Gage FH. Neurogenesis in the dentate gyrus of the adult rat: age-related decrease of neuronal progenitor proliferation. J Neurosci 1996;16:2027-33.

27. Coggeshall RE, Lekan HA. Methods for determining numbers of cells and synapses: a case for more uniform standards of review. J Comp Neurol 1996;364:6-15.

28. Wu W, Wong K, Chen J, Jiang Z, Dupuis S, Wu JY, et al. Directional guidance of neuronal migration in the olfactory system by the protein Slit. Nature 1999;400:331-6.

29. Lois C, García-Verdugo JM, Alvarez-Buylla A. Chain migration of neuronal precursors. Science 1996;271:978-81.

30. Kakita A, Goldman JE. Patterns and dynamics of SVZ cell migration in the postnatal forebrain: monitoring living progenitors in slice preparations. Neuron 1999;23:461-72.

31. McKay R. Stem cells in the central nervous system. Science 1997; 276:66-71.

32. Lendahl U, Zimmerman LB, McKay RD. CNS stem cells express a new class of intermediate filament protein. Cell 1990;60:585-95.

33. Rakic P. Mode of cell migration to the superficial layers of fetal monkey neocortex. J Comp Neurol 1972;145:61-83.

34. Soriano E, Alvarado-Mallart RM, Dumesnil N, Del Río JA, Sotelo C. Cajal-Retzius cells regulate the radial glia phenotype in the adult and developing cerebellum and alter granule cell migration. Neuron 1997;18:563-77.

35. Jinnou H, Sawada M, Kawase K, Kaneko N, Herranz-Pérez V, Mi- yamoto $\mathrm{T}$, et al. Radial glial fibers promote neuronal migration and functional recovery after neonatal brain injury. Cell Stem Cell 2018;22:128-37.

36. Craig CG, Tropepe V, Morshead CM, Reynolds BA, Weiss S, van der Kooy D. In vivo growth factor expansion of endogenous subependymal neural precursor cell populations in the adult mouse brain. J Neurosci 1996;16:2649-58.

37. Kuhn HG, Winkler J, Kempermann G, Thal LJ, Gage FH. Epidermal growth factor and fibroblast growth factor-2 have different effects on neural progenitors in the adult rat brain. J Neurosci 1997; 17:5820-9.

38. Im SH, Yu JH, Park ES, Lee JE, Kim HO, Park KI, et al. Induction of striatal neurogenesis enhances functional recovery in an adult animal model of neonatal hypoxic-ischemic brain injury. Neuroscience 2010;169:259-68.

39. Cho JH, Tsai MJ. The role of BETA2/NeuroD1 in the development of the nervous system. Mol Neurobiol 2004;30:35-47.

40. Huang L, Zhang L. Neural stem cell therapies and hypoxic-ischemic brain injury. Prog Neurobiol 2019;173:1-17.

41. Plane JM, Liu R, Wang TW, Silverstein FS, Parent JM. Neonatal hypoxic-ischemic injury increases forebrain subventricular zone neurogenesis in the mouse. Neurobiol Dis 2004;16:585-95.

42. Felling RJ, Snyder MJ, Romanko MJ, Rothstein RP, Ziegler AN, Yang Z, et al. Neural stem/progenitor cells participate in the regenerative response to perinatal hypoxia/ischemia. J Neurosci 2006;26:4359-69.

43. Yang Z, Covey MV, Bitel CL, Ni L, Jonakait GM, Levison SW. Sustained neocortical neurogenesis after neonatal hypoxic/ischemic injury. Ann Neurol 2007;61:199-208.

44. Tobin MK, Bonds JA, Minshall RD, Pelligrino DA, Testai FD, Lazarov $\mathrm{O}$. Neurogenesis and inflammation after ischemic stroke: what is known and where we go from here. J Cereb Blood Flow Metab 2014;34:1573-84.

45. Li L, Harms KM, Ventura PB, Lagace DC, Eisch AJ, Cunningham LA. Focal cerebral ischemia induces a multilineage cytogenic response from adult subventricular zone that is predominantly gliogenic. Glia 2010;58:1610-9.

46. Faiz M, Sachewsky N, Gascón S, Bang KW, Morshead CM, Nagy A. Adult neural stem cells from the subventricular zone give rise to reactive astrocytes in the cortex after stroke. Cell Stem Cell 2015; 17:624-34.

47. Lee IS, Koo KY, Jung K, Kim M, Kim IS, Hwang K, et al. Neurogenin-2-transduced human neural progenitor cells attenuate neonatal hypoxic-ischemic brain injury. Transl Res 2017;183:121-36.

48. Cho M, Jung K, Kim SH, Kim IS, Kim M, Shin M, et al. Safety and efficacy evaluations of an adeno-associated virus variant for preparing IL10-secreting human neural stem cell-based therapeutics. Gene Ther 2019;26:135-50.

49. Kriegstein A, Alvarez-Buylla A. The glial nature of embryonic and adult neural stem cells. Annu Rev Neurosci 2009;32:149-84.

50. Fagel DM, Ganat Y, Silbereis J, Ebbitt T, Stewart W, Zhang H, et al. Cortical neurogenesis enhanced by chronic perinatal hypoxia. Exp Neurol 2006;199:77-91.

51. Ganat Y, Soni S, Chacon M, Schwartz ML, Vaccarino FM. Chronic hypoxia up-regulates fibroblast growth factor ligands in the perinatal brain and induces fibroblast growth factor-responsive radial glial cells in the sub-ependymal zone. Neuroscience 2002;112:977-91.

52. Ong J, Plane JM, Parent JM, Silverstein FS. Hypoxic-ischemic injury stimulates subventricular zone proliferation and neurogenesis in the neonatal rat. Pediatr Res 2005;58:600-6.

53. Yang Z, Levison SW. Perinatal hypoxic/ischemic brain injury induces persistent production of striatal neurons from subventricular zone progenitors. Dev Neurosci 2007;29:331-40. 
54. Zaidi AU, Bessert DA, Ong JE, Xu H, Barks JD, Silverstein FS, et al. New oligodendrocytes are generated after neonatal hypoxic-ischemic brain injury in rodents. Glia 2004;46:380-90.

55. Back SA, Tuohy TM, Chen H, Wallingford N, Craig A, Struve J, et al. Hyaluronan accumulates in demyelinated lesions and inhibits oligodendrocyte progenitor maturation. Nat Med 2005;11:966-72.

56. Pendleton JC, Shamblott MJ, Gary DS, Belegu V, Hurtado A, Malone ML, et al. Chondroitin sulfate proteoglycans inhibit oligodendrocyte myelination through РTPб. Exp Neurol 2013;247: 113-21.

57. Bain JM, Ziegler A, Yang Z, Levison SW, Sen E. TGF $\beta 1$ stimulates the over-production of white matter astrocytes from precursors of the "brain marrow" in a rodent model of neonatal encephalopathy. PLoS One 2010;5:e9567.

58. Sabo JK, Heine V, Silbereis JC, Schirmer L, Levison SW, Rowitch $\mathrm{DH}$. Olig1 is required for noggin-induced neonatal myelin repair. Ann Neurol 2017;81:560-71.

59. Faigle R, Song H. Signaling mechanisms regulating adult neural stem cells and neurogenesis. Biochim Biophys Acta 2013;1830: 2435-48.

60. Semple BD, Blomgren K, Gimlin K, Ferriero DM, Noble-Haeusslein LJ. Brain development in rodents and humans: identifying benchmarks of maturation and vulnerability to injury across species. Prog Neurobiol 2013;106-107:1-16.

61. Lehner B, Sandner B, Marschallinger J, Lehner C, Furtner T, Couillard-Despres S, et al. The dark side of BrdU in neural stem cell biology: detrimental effects on cell cycle, differentiation and survival. Cell Tissue Res 2011;345:313-28.

62. Duque A, Spector R. A balanced evaluation of the evidence for adult neurogenesis in humans: implication for neuropsychiatric disorders. Brain Struct Funct 2019;224:2281-95.

63. Satoh T, Fekete DM. Retroviral vectors to study cell differentiation. Front Biosci 2003;8:d183-92.

64. Cooray S, Howe SJ, Thrasher AJ. Retrovirus and lentivirus vector design and methods of cell conditioning. Methods Enzymol 2012; 507:29-57. 